\title{
Association of Parental Origin with Phenotypic Profile in Turner Syndrome
}

Sayee Rajangam ${ }^{1}$, Vallabhajosyula Ranganath ${ }^{2^{*}}$ and Leelavathy $\mathbf{N}^{3}$

${ }^{1}$ Department of Anatomy, International Medical School, Bangalore, India

${ }^{2}$ PUGSOM, Perdana University, Selangor, Malaysia

${ }^{3}$ Department of Anatomy, Oxford Medical College, Bangalore, India

"Corresponding author: Ranganath V, Associate Professor, Hall 'D', Level 1, MAEPS building, MARDI complex, University Putra Malaysia, 43400, Selangor, Malaysia, Tel: +60137955485; E-mail: ranganath@perdanauniversity.edu.my

Rec Date: March 23, 2015; Acc Date: Apr 17, 2015; Pub Date: Apr 21, 2015

Copyright: (c) 2015 Ranghanath V, et al. This is an open-access article distributed under the terms of the Creative Commons Attribution License, which permits unrestricted use, distribution, and reproduction in any medium, provided the original author and source are credited.

\begin{abstract}
Objective: The objective of the study is to report the association between the phenotype of the Turner syndrome with that of its karyotype and the parental origin of the X. 181 female referred to division of human genetics, St. John's Medical College with different referral reasons are included in 1st phase of the study to observe the karyotype, upon obtaining the consent. Families of probands with confirmed pure or mosaic (more than $10 \%$ of mosaic status) karyotype of Turner stigmata are requested to participate in 2 nd phase of study to determine the parent of origin. 20 families agreed and gave the consent for the study.
\end{abstract}

Material and Method: The Karyotype analsyis was carried by GTG banding method automated karyotyping system. The parental origin was determined by $X$ chromosome specific short tandem repeat (STR) markers. 23 Turner stigmata features were listed in the proforma. The secondary measure is to observe the associated Turner stigmata with the determined karyotype and the parental origin.

Results: In 11 female probands, one had X structural abnormality $(45, \mathrm{X} / 46, \mathrm{X}, \mathrm{i}(\mathrm{Xq}))$; 2 had X-mosaicism (45,X/ $46, X X)$ and 8 had $45, X$. The determined parental origin of $X$ was maternal in $8(72.7 \%)$ and paternal in $3(27.2 \%)$.

23 phenotypic features of Turner stigmata were tabulated. The features were further categorized as general observations, classical features of TS, features based on ultrasound findings and behavior. Percentage analysis indicated that a higher concordance of phenotype and behavior in proband with maternal $\mathrm{X}$.

Conclusion: In the present study, the Turner syndrome features were seemed to be associated with the maternal origin of $X$ in Turner syndrome.

Keywords: Karyotype; Phenotypic profile; Turner syndrome; Cardiovascular disorders; Visual acuity

\section{Introduction}

Normal female possesses XX chromosome one derived from mother (Xm) and other from father (Xp). Turner syndrome (TS), an sex chromosomal aneuploidy seen in female with 45,X karyotype in more than $50 \% ; 30 \%$ to $40 \%$ are mosaic and the rest with structural changes. The most commonly seen structural chromosomal abnormality is isochromosome formation followed by ring formation and the other types [1]. Molecular studies have shown that approximately $60 \%$ to $80 \%$ of monosomy is due to absence of paternally derived $\mathrm{X}$ that occur either during mitosis in the embryo or meiosis in the father [2]. The phenotypic clinical profile in TS is variable for unknown reasons. It is speculated that the variability depends on origin of X. Retrospective studies indicate that the sociocognitive features, social IQ and other behavioural activities in TS are associated with Xp (paternally derived) suggesting the existence of expression of genes of different genetic loci from the parent's X [3-6]. Association of parental origin with cardiovascular disorders [7], high degree of social activity, verbal and communications skills, visual acuity and memory are reported [8].
The findings from the existing literature clearly depict the variability of clinical profile with reference to parental origin primarily on socio-cognitive profile. There exists some paucity in literature to associate the karyotype, clinical profile with parental origin and correlation of the findings. Thus, the present study, attempted to correlate the phenotype with genotype i.e., the karyotype and the parental origin of $\mathrm{X}$ in TS.

\section{Material and Method}

The Sample consisted 181 female individuals referred to division of Human Genetics, Department of Anatomy, SJMC, Bangalore, with primary amenorrhea (PAm) as the main chief complaint and the other complaints were such as TS (?), Secondary Amenorrhea (SA), Bad Obstretric History (BOH), Primary Infertility (PI), Growth Retardation (GR), Ambiguous Genitalia (AG), Multiple Congenital Anomalies (MCA), Primary Ovarian Failure (POF), Sexual Infantilism and Very Obese. At the time of referral, a clinical proforma was documented to report the expressed phenotypic features of the proband. With the informed consent, cytogenetic analysis was performed by conventional karyotyping method (Peripheral lymphocyte culture) and automated karyotyping system (Applied Biosystems). 
Citation: Rajangam S, Ranganath V, Leelavathy N (2015) Association of Parental Origin with Phenotypic Profile in Turner Syndrome . Human Genet Embryol 5: 1000126. doi:10.4172/2161-0436.1000126

Page 2 of 4

The consent to determine the parental origin was obtained after karyotype confirmation. 20 TS female and families have given consent for parental origin detection. DNA was extracted from the proband and parents by modified phenol-chloroform method (Thangraj et al.) [9]. Quantification of DNA was carried by gel electrophoresis method. $\mathrm{X}$ chromosome specific STR (Short Tandem Repeat) markers of definite primer length used to amplify the DNA of proband and parents under specific PCR settings (BIORAD). The amplified product was subjected to GENE SCAN (Applied Biosystems 3730) for parental origin determination. The results of GENE SCAN was analyzed and interpreted in GENEMAPPER (ABI Prism Linkage mapping sets v2.5 user's manual)

The listed phenotypic features that were documented are correlated with karyotype and the originated X. A percentage analysis was carried out to report the entire documented and observed data.

\begin{tabular}{|l|l|l|l|l|}
\hline SI.No & Karyotype & $\mathbf{n ~ 1 1 ; \%}$ & $\mathbf{X m ~ n ~ 8 ; ~ \% ~}$ & $\mathrm{Xp} \mathrm{n} \mathrm{3;} \mathrm{\%}$ \\
\hline 1 & $45, \mathrm{X}$ & $8 ; 72.72$ & $6 ; 75$ & $2 ; 25$ \\
\hline 2 & $45, \mathrm{X} / 46, \mathrm{XX}$ & $2 ; 18.18$ & $1 ; 50$ & $1 ; 50$ \\
\hline 3 & $45, \mathrm{X} / 46, \mathrm{X}, \mathrm{i}(\mathrm{Xq})$ & $1 ; 9.09$ & $1 ; 100$ & - \\
\hline
\end{tabular}

Table 1: TS: Parental origin vs. karyotype (n11).

\section{Results}

The parental origin could be determined in 11 (55\%) families with TS proband. Maternal origin of the X chromosome was confirmed in $72.7 \%$ (8) and paternal in $27.3 \%$ (3).

Table 1 shows the determined karyotype of 11 TS probands with the parental origin of X. 45,X karyotype was observed in $72.72 \%$ (8) cases out of which $75 \%$ (6) showed maternally derived X (Xm) and 25\% (2) paternally derived X (Xp).

\begin{tabular}{|c|c|c|c|}
\hline \multirow[t]{2}{*}{ SI.no } & \multirow[t]{2}{*}{ Features } & \multicolumn{2}{|l|}{ TS (11) } \\
\hline & & $\mathrm{Xm}(8)$ & $\mathrm{Xp}(3)$ \\
\hline \multirow[t]{6}{*}{1.} & \multicolumn{3}{|c|}{ Chief complaints at the time of referral } \\
\hline & Primary amenorrhea (PA) & 4 & 1 \\
\hline & ?TS & 2 & - \\
\hline & Short Stature & 1 & 1 \\
\hline & Dysmorphic features & 1 & - \\
\hline & Infertility & & 1 \\
\hline \multirow[t]{4}{*}{2.} & \multicolumn{3}{|c|}{ Age at the time of referral (in years) } \\
\hline & $0-10$ & 1 & 1 \\
\hline & $11-20$ & 7 & 1 \\
\hline & $21-30$ & & 2 \\
\hline \multirow[t]{4}{*}{3.} & \multicolumn{3}{|l|}{ Birth order } \\
\hline & 1 & 4 & - \\
\hline & 2 & 2 & 2 \\
\hline & 3 & 1 & 1 \\
\hline
\end{tabular}

\begin{tabular}{|c|c|c|c|}
\hline & 10 & 1 & - \\
\hline \multirow[t]{3}{*}{4.} & \multicolumn{3}{|c|}{ Maternal age at conception (in years) } \\
\hline & $16-20$ & 4 & 2 \\
\hline & $21-30$ & 4 & 1 \\
\hline \multirow[t]{4}{*}{5.} & \multicolumn{3}{|c|}{ Paternal age at conception (in years) } \\
\hline & $21-30$ & 3 & - \\
\hline & $31-40$ & 5 & 2 \\
\hline & $41-50$ & - & 1 \\
\hline \multirow[t]{3}{*}{6.} & \multicolumn{3}{|l|}{ Consanguinity } \\
\hline & 1st cousin & - & 1 \\
\hline & Uncle-neice & 2 & - \\
\hline \multirow[t]{4}{*}{7.} & \multicolumn{3}{|l|}{ Education } \\
\hline & Secondary schooling & 5 & 1 \\
\hline & Preuniversity education & 1 & - \\
\hline & Graduation & - & 2 \\
\hline \multirow[t]{3}{*}{8.} & \multicolumn{3}{|l|}{ Behaviour } \\
\hline & Normal & 5 & 3 \\
\hline & Subnormal & 3 & - \\
\hline \multirow[t]{4}{*}{9.} & \multicolumn{3}{|l|}{ Height (in cms) } \\
\hline & $<120$ & 1 & 1 \\
\hline & $120-140$ & 4 & - \\
\hline & $>140$ & 3 & 2 \\
\hline \multirow[t]{2}{*}{10.} & \multicolumn{3}{|l|}{ Stature } \\
\hline & Short & 4 & 2 \\
\hline 11. & Low hair line & 2 & - \\
\hline 12. & Webbed neck & 4 & - \\
\hline 13. & Lymphedema & 1 & - \\
\hline \multirow[t]{3}{*}{14.} & \multicolumn{3}{|l|}{ Breast development } \\
\hline & Hypoplastic & 2 & 2 \\
\hline & Not developed & 5 & 1 \\
\hline 15. & Far apart nipple position & 2 & 1 \\
\hline \multirow[t]{3}{*}{16.} & \multicolumn{3}{|l|}{ Axillary hair growth } \\
\hline & Absent & 5 & 2 \\
\hline & Scanty & 1 & 1 \\
\hline 17. & Shield shaped chest & 2 & - \\
\hline 18. & Cubitus valgus & 3 & - \\
\hline \multirow[t]{2}{*}{19.} & \multicolumn{3}{|l|}{ Pubic hair growth } \\
\hline & Absent & 5 & 1 \\
\hline
\end{tabular}




\begin{tabular}{|l|l|l|l|}
\hline & Scanty & 1 & 2 \\
\hline 20. & Ultrasound findings & 3 & 1 \\
\hline & Hypoplastic uterus & 2 & - \\
\hline & Infantile uterus & 4 & 1 \\
\hline & Streak gonads & 6 & 3 \\
\hline 21. & Not attained menarche & & \\
\hline 22. & Karyotype & 6 & 2 \\
\hline & $45, \mathrm{X}$ & 1 & 1 \\
\hline & $45, \mathrm{X} / 46, \mathrm{XX}$ & 1 & - \\
\hline & $45, \mathrm{X} / 46, \mathrm{X}, \mathrm{i}(\mathrm{Xq})$ & & \\
\hline
\end{tabular}

observations of the present study, 54.5\% Xm and $18.18 \% \mathrm{Xp}$ with $45, \mathrm{X}$ karyotype was within the reported range.

Association of TS stigmata with Xm was observed to be on higher side than the reported finding from the literature. It was observed in the present study that except for the reproductive system, TS with Xm or Xp origin did not manifest any abnormal systemic features. As stated in literature $[8,15]$ in the present study too, the association OF the pheotypic features and parental origin was minimal, with more concordance with Xm

In the present study, features were categorized into 23 groups that are gathered from proforma (two parts for ultra sound findings uterus and ovary). The calculated total numbers of 23 features are multiplied for the sample of 11 was 264 . Irrespective of the parental origin, the TS females manifested $54.1 \%$ of the abnormal TS features. Out of which, with Xm [8], the manifestation of phenotypic features was $73.42 \%$ and with $\mathrm{Xp}[3]$, it was $26.57 \%$.

Table 2: TS parental origin with general and clinical features.

$\mathrm{X}$-mosaicism, the next common karyotype in TS was present in 2 and the parental origin was of equal percentage. The structural anomaly for $\mathrm{X}$ i.e.' iso chromosome for $\mathrm{Xq}$ was observed in one and the normal $\mathrm{X}$ of that case was found to be maternal. The features that were framed in the TS proforma were listed in Table 2. The observed TS features are tabulated against the determined parental origin. The interesting observation was the behavior of TS probands. Subnormal behavior was observed in 3 TS probands with Xm. All the TS female with Xp showed normal behavior. The documented TS stigmata such as low hair line, webbed neck, lymphedema, cubitus valgus, absence of axillary and pubic hair growth (secondary sexual character), hypoplastic and infantile uterus, streak gonads was high in Xm derived TS probands. Abnormality of paramesonephric derivatives are confirmed by ultrasound findings.

\section{Discussion}

The investigations to determine the parental origin were carried out either on single case or in a number of selective cases with 45 , X or Xmosaicism or X-structural abnormality. Boczkowski in 1966 [10] based on Xg blood grouping, determined the maternal origin of single $\mathrm{X}$ in one patient; Schinzel et al. [11] in 1993 with X-linked molecular probes, reported the maternally originated $\mathrm{X}$ in one patient; Krajinovic et al. [12] in 1994 based on polymorphic microsatellite markers determined the paternally derived X in one patient; Pasarell et al. [13] in 1999 with PCR based polymorphic microsatellite markers, determined the maternally and paternally derived $\mathrm{X}$ in two cases and da Silva et al. [14] in 2006 reported the maternally derived X in one patient based on PCR based polymorphic microsatellite markers. A high percentage was noticed for maternally derived X. It was observed from the literature that the reported percentage of maternally derived $\mathrm{X}$. The observations of the present study were within the reported range for each category. The observations of the present study for maternally derived X $(\mathrm{Xm})(72 \%, 8)$ and paternally derived $\mathrm{X}(\mathrm{Xp})$ $(28 \%, 3)$ were similar to the study by Mathur et al. [15] (72\% Xm; $28 \%$ $\mathrm{Xp})$. The findings of the maternal origin of $72 \%$ in the present study may be interpreted that a higher percentage of paternal X might have been lost from the normal female $(46, \mathrm{XX})$ or male $(46, \mathrm{XY})$ zygote.

The parental origin of $\mathrm{X}$ was determined mostly in probands with $45, \mathrm{X}$, because the incidence of that karyotype in TS is around 40 to $50 \%$. The reported range of Xm with 45 , X was 36.70 [5] to $68.75 \%$ [16] and for Xp with $45, X$, the range was 12.76 [5] to $20.37 \%$ [17]. The

The observation of $54.1 \%$ of the manifestation of TS features, in the present study, could be interpreted that, in Indian women, the severity of the features were more associated with $\mathrm{Xm}$. From, the findings it could be opined, that out of the listed features, in case scoring is carried out, any suspected TS with 50\% scoring and above might have $\mathrm{X}$ and a similar prediction could be applied for Xp. From the findings, it is seen, thus, a TS diagnostic criteria has emerged for the individuals with TS in India.

\section{Conclusion}

In TS, out of 11, structural abnormality of $\mathrm{X}$ was observed in one with the determined karyotype of 45,X/46,X,i(Xq); 2 had X-mosaicism $(45, \mathrm{X} / 46, \mathrm{XX})$ and the remaining 8 had $45, \mathrm{X}$. Parental origin of $\mathrm{X}$ was determined in 11 cases. The maternal origin in TS was $72.7 \%$ [8] and paternal in $3(27.2 \%)$. On correlation, in TS, it was observed that $\geq$ $50 \%$ of probands with maternally derived X, showed high degree of TS Stigmata which can correlated with chief complaint and age at the time referral. The 23 features were listed from TS proforma showed the manifestation of $54.16 \%$ of abnormal TS features irrespective of parental origin. Out of which, with $\mathrm{Xm}$ [8], the manifestation of phenotypic features was $73.42 \%(105 / 143)$ and with Xp [3], it was $26.57 \%$

The observations of features in TS, could be interpreted that, in Indian women, the severity of the features were associated with TS females with Xm.

\section{Acknowledgements}

We sincerely thank Dr Thangaraj CCMB Hyderabad and Dr Rajender Singh CDRI Lucknow for their immense help and support in carrying out parental origin study.

\section{References}

1. Jorde LB, Carey JC, Bamshad MJ, White RL (2009) The chromosomal basis of Human Disease: Medical Genetics (4thedn) Mosby, Elsevier Philadelphia.

2. Jacobs P, Hassold T, Harvey J, May K (1989) The origin of sex chromosome aneuploidy. Prog Clin Biol Res 311: 135-151.

3. Hassold T, Pettay D, Robinson A, Uchida I (1992) Molecular studies of parental origin and mosaicism in $45, \mathrm{X}$ conceptuses. Hum Genet 89: 647-652. 
Citation: Rajangam S, Ranganath V, Leelavathy N (2015) Association of Parental Origin with Phenotypic Profile in Turner Syndrome . Human Genet Embryol 5: 1000126. doi:10.4172/2161-0436.1000126

Page 4 of 4

4. Jacobs PA, Betts PR, Cockwell AE, Crolla JA, Mackenzie MJ, et al. (1990) A cytogenetic and molecular reappraisal of a series of patients with Turner's syndrome. Ann Hum Genet 54: 209-223.

5. Jacobs P, Dalton P, James R, Mosse K, Power M, et al. (1997) Turner syndrome: a cytogenetic and molecular study. Ann Hum Genet 61: 471-483.

6. Larsen T, Gravholt CH, Tillebeck A, Larsen H, Jensen MB, et al. (1995) Parental origin of the $\mathrm{X}$ chromosome, $\mathrm{X}$ chromosome mosaicism and screening for "hidden" $\mathrm{Y}$ chromosome in 45,X Turner syndrome ascertained cytogenetically. Clin Genet 48: 6-11.

7. Chu CE, Donaldson MD, Kelnar CJ, Smail PJ, Greene SA, et al. (1994) Possible role of imprinting in the Turner phenotype. J Med Genet 31: 840-842.

8. Skuse DH, James RS, Bishop DV, Coppin B, Dalton P, et al. (1997) Evidence from Turner's syndrome of an imprinted X-linked locus affecting cognitive function. Nature 387: 705-708.

9. Thangaraj K, Joshi MB, Reddy AG, Gupta NJ, Chakravarty B, et al. (2002) CAG repeat expansion in the androgen receptor gene is not associated with male infertility in Indian populations. J Androl 23 815-818.

10. Boczkowski K (1966) Maternal age and the source of the X chromosome in an XO girl. Am J Obstet Gynecol 95: 593-594.

11. Schinzel AA, Robinson WP, Binkert F, Torresani T, Werder EA (1993) Exclusively paternal X chromosomes in a girl with short stature. Hum Genet 92: 175-178.
12. Krajinovic M, Ivanovic K, Mestroni L, Diklic V, Nikolis J (1994) Parental origin of the $\mathrm{X}$ chromosome in a patient with a Robertsonian translocation and Turner's syndrome. J Med Genet 31: 255-256.

13. Martínez-Pasarell O, Templado C, Vicens-Calvet E, Egozcue J, Nogués C (1999) Paternal sex chromosome aneuploidy as a possible origin of Turner syndrome in monozygotic twins: case report. Hum Reprod 14: 2735-2738.

14. da Silva AL, Ferreira de Lima R, Ribeiro AL, Ferreira-Moretti D (2006) X monosomy and balanced Robertsonian translocation in a girl with Turner syndrome. Genet Mol Biol 29(1): 47-48.

15. Mathur A, Stekol L, Schatz D, MacLaren NK, Scott ML, et al. (1991) The parental origin of the single $\mathrm{X}$ chromosome in Turner syndrome: lack of correlation with parental age or clinical phenotype. Am J Hum Genet 48: 682-686.

16. Sagi L, Zuckerman-Levin N, Gawlik A, Ghizzoni L, Buyukgebiz A, et al. (2007) Clinical significance of the parental origin of the X chromosome in turner syndrome. J Clin Endocrinol Metab 92: 846-852.

17. Hamelin CE, Anglin G, Quigley CA, Deal CL (2006) Genomic imprinting in Turner syndrome: effects on response to growth hormone and on risk of sensorineural hearing loss. J Clin Endocrinol Metab 91: 3002-3010. 